\title{
Resilience Management in Social-ecological Systems: a Working Hypothesis for a Participatory Approach
}

Brian Walker ${ }^{1 \mathrm{a}}$, Stephen Carpenter ${ }^{2}$, John Anderies ${ }^{\text {lb }}$, Nick Abel ${ }^{1 \mathrm{~b}}$, Graeme Cumming ${ }^{3}$, Marco Janssen ${ }^{4}$, Louis Lebel $^{5}$, Jon Norberg ${ }^{6}$, Garry D. Peterson ${ }^{2}$, and Rusty Pritchard ${ }^{7}$

ABSTRACT. Approaches to natural resource management are often based on a presumed ability to predict probabilistic responses to management and external drivers such as climate. They also tend to assume that the manager is outside the system being managed. However, where the objectives include long-term sustainability, linked social-ecological systems (SESs) behave as complex adaptive systems, with the managers as integral components of the system. Moreover, uncertainties are large and it may be difficult to reduce them as fast as the system changes. Sustainability involves maintaining the functionality of a system when it is perturbed, or maintaining the elements needed to renew or reorganize if a large perturbation radically alters structure and function. The ability to do this is termed "resilience." This paper presents an evolving approach to analyzing resilience in SESs, as a basis for managing resilience. We propose a framework with four steps, involving close involvement of SES stakeholders. It begins with a stakeholder-led development of a conceptual model of the system, including its historical profile (how it got to be what it is) and preliminary assessments of the drivers of the supply of key ecosystem goods and services. Step 2 deals with identifying the range of unpredictable and uncontrollable drivers, stakeholder visions for the future, and contrasting possible future policies, weaving these three factors into a limited set of future scenarios. Step 3 uses the outputs from steps 1 and 2 to explore the SES for resilience in an iterative way. It generally includes the development of simple models of the system's dynamics for exploring attributes that affect resilience. Step 4 is a stakeholder evaluation of the process and outcomes in terms of policy and management implications. This approach to resilience analysis is illustrated using two stylized examples.

\section{INTRODUCTION}

A fundamental difficulty in managing socialecological systems (SESs) for long-term, sustainable outcomes is that their great complexity makes it difficult to forecast the future in any meaningful way. Not only are forecasts uncertain, the usual statistical approaches will likely underestimate the uncertainties. That is, even the uncertainties are uncertain. There are several reasons why uncertainties are large and difficult to characterize:

- Key drivers, such as climate and technological change, are unpredictable. Many change nonlinearly.

- Human action in response to forecasts is reflexive. If important ecological or economic predictions are taken seriously, people will react in ways that will change the future, and perhaps cause the predictions to be incorrect.

- The system may change faster than the forecasting models can be recalibrated, particularly during turbulent periods of transition, so forecasts are most unreliable in precisely the situations where they are most wanted.

These aspects of uncertainty limit the usefulness of forecasting methods for the scientific study and management of regions in transition. Given these limits to understanding, we must focus on learning to live within systems, rather than "control" them. One might argue that it is impossible to deal with such fundamental limits of understanding, and our only reasonable choice is to struggle blindly onward.

However, SESs might not be so unpredictable if

\footnotetext{
${ }^{1 a}$ Corresponding author: CSIRO Sustainable Ecosystems, P.O. Box 284, Canberra ACT 2601 Australia, Phone: 61-2-6242-1740, Fax: 61-02-6241-1742, Email: Brian.Walker@csiro.au

${ }^{1 b}$ CSIRO Sustainable Ecosystems; ${ }^{2}$ Center for Limnology, University of Wisconsin-Madison; ${ }^{3}$ University of Florida; ${ }^{4}$ Indiana University; ${ }^{5}$ University of Chiang Mai; ${ }^{6}$ Department of Systems Ecology, Stockholm University; ${ }^{7}$ Emory University
} 
their behavior were looked at from a larger perspective, ignoring such details as agents and variables, and concentrating on the coarse-grained features of the system. For example, we know that systems undergo change, but we also recognize that there are periods of perceived constancy. We know that both social and ecological systems have selfreinforcing mechanisms that prevent shifts into other configurations (Folke et al. 1998, Gunderson and Holling 2002). Complexity theory tries to describe these phases and the underlying mechanisms that give rise to them, and variables that affect these mechanisms. The most notable contribution to this body of theory from an ecological perspective is Holling's (1992) metaphor of the adaptive cycle. Growing out of a general understanding of largescale ecosystem behavior (e.g., Gunderson et al. 1995), the adaptive cycle appears to be applicable to SESs. In this paper, we propose using a general understanding of complex system behavior to guide how possible scenarios for SESs might be envisioned, analyzed, and managed in terms of their resilience.

An alternative approach to methods based on forecasting is to set decision analysis aside, and focus instead on maintaining the capacity of the system to cope with whatever the future brings, without the system changing in undesirable ways. This can be done by maintaining or increasing the system's resilience (defined carefully in the next section). Building this resilience will come at a cost, so we need to ask: When does it make sense to build resilience and what is the best way to do it for a particular SES? The framework presented here offers an approach to analyzing resilience and enabling people to discover how the SES in which they live might be made more resilient to shocks, and more able to renew or reorganize itself should large shocks occur. We term this approach "resilience analysis and management."

Understanding the loss, creation, and maintenance of resilience through the process of co-discovery (by scientists, policy makers, practitioners, stakeholders, and citizens) is at the heart of sustainability (Gunderson and Holling 2002). But how can codiscovery be fostered? There are many partial theories, but few that deal with linked SES dynamics. Because the theory is lacking, we must be inductive and, accordingly, we must base theory development on comparative analyses of different case studies.
This paper arose out of a research program in the Resilience Alliance, aimed at trying to understand how resilience changes in regional-scale SESs, and how it might be increased, or lost, through management. It builds on a rich history of empirical work and theoretical development by a number of earlier researchers, notably C. S. (Buzz) Holling and colleagues (Holling 1973, 1978, 1986, 1995, 2001, Walters 1986). Others who have explored the complex systems basis of natural resource management include Checkland (1981), Allen and Hoekstra (1992) and Levin (1999). Managers, engineers, activists, and researchers have developed a range of methods to deal with challenges in complex business situations (e.g., Checkland's (1981; Checkland and Scholes 1999) soft systems methodology), and yet others have developed approaches to cope with human-ecological situations (Kay et al. 1999). Many methods have been developed for working with stakeholders (Slocum et al. 1995) and conceptualizing complex situations, e.g., work on "learning organizations" (Senge 1990), policy exercises (Toth 1988), participatory integrated assessment (van de Kerkhof 2001), companionable modeling and role games (Bousquet et al. 2002), and participatory geographic information systems (Craig et al. 2002). We, the authors of this paper, have had experience with a diverse set of methods and approaches regarding the assessment of complex systems involving people and nature, ranging from the early adaptive management approaches through scenario planning (van der Heijden 1996) to participatory learning and action (Pretty et al. 1995), and we have incorporated aspects of these approaches into the framework we present here. Several of the individual components we propose are not, therefore, new concepts. We acknowledge their development by others and use them in the development of this framework, which we offer as a further step toward achieving an integrated approach to understanding and assessing resilience and discovering where it resides in linked social-ecological systems. This is the novel part of what we propose. The need for such an approach was well expressed in the recent report by Kinzig et al. (2000)

The present paper is one milestone in an ongoing project. It crystallizes our current understanding of resilience building for SESs. As with any pragmatic approach, it is sure to be partial. Significant revisions to our approach will likely be necessary in the future, as we learn by doing. In particular, as we 
note below, we would like to build on this approach for work in contexts where there are many overlapping local systems with shared problems, but with competing systems of governance, where the prospect of regional-scale decision making is extremely problematic. As it stands, the framework is probably limited by our western, developed-world optic on management, with which we constantly struggle. We maintain, however, that the issues we raise are even more salient in the context of the developing world, and so we offer this foundation on which to build.

\section{THE APPROACH}

The goal of resilience management is to prevent an SES from moving into undesirable configurations. It depends on the system being able to cope with external shocks in the face of irreducible uncertainty. In turn, this requires understanding where resilience resides in the system, and when and how it can be lost or gained. We wish, therefore, to discover the points of intervention in an SES where one can increase resilience of desired configurations to future changes, including those that are unforeseeable. The process of attempting to increase resilience to unforeseeable change is different from attempting to improve system performance during times of stability and growth, as exemplified by a decision analysis approach. Both are necessary but, to date, the emphasis in human-used ecosystems has been strongly on the latter. In decision analysis, possible policies are evaluated using the probability distribution of system trajectories that each candidate policy generates. The decision analysis process identifies the policy that maximizes expected utility, or minimizes expected regrets (losses).

In choosing policies for an SES, such a decision analysis has limited value, for a number of reasons. Some necessary probability distributions are unknown; there are many decision makers with different utility functions (i.e., there is no single measure of utility or loss that adequately captures all the values of different stakeholders within the system); some utility functions are yet to be constructed (stakeholders may not know what stakes they hold); very importantly, decision analysis does not capture the capacity of people to react to forecasts of future conditions by creating novel visions of the future and, thus, change the future by acting upon them. Finally, although well developed as analytical tools, policies resulting from optimization procedures are seldom applied because in a more-or-less democratic, pluralistic, capitalist society, policies are the product of interactions among voters, business and industry, interest groups, informal and formal institutions, politicians and bureaucrats, and international actors governing development assistance, monetary policy, and trade regimes. Election cycles are brief, trade-offs are necessary if elections are to be won, and policies are usually made hurriedly and pragmatically. Similar but more severe deviations from optimal policies characterize non-democratic and less pluralistic societies.

In addition to decision analysis, the conventional maximum-yield/minimum-regrets approaches are well supported by such techniques as simulation gaming, integrated assessment, decision support systems, cost-benefit analysis, and multi-criteria analysis. But these are techniques used to propose resource allocation that require the real system to be represented by a model that makes probabilistic predictions. If the actual system behavior gets too far away from the model representation, the predictions fail. The failure of "Long-term Capital Management" is an example (Lowenstein 2000). This enterprise used a decision rule based on a representation of the system that assumed a particular distribution for share price fluctuations. The actual system behaved within reasonable range of these assumptions and the decision rule (in a very uncertain environment) worked very well. However, after the Asian financial collapse (Krugman 2000), the real system deviated from the model representation upon which the decision rule was based and performance of the company plummeted. The developers of this framework knew this to be the case and could have put more weight on the possibility of a Thailand economic problem, thus changing their strategy, but consciously chose not to. Resilience analysis is based on a conscious choice to put extra weight on "outliers," on the assumption that ecosystems are more prone to such behavior than are share prices, futures prices, or exchange rates.

We offer resilience analysis as an approach that highlights the fact that the assumptions underpinning conventional decision analysis frequently do not hold. The evidence of unexpected and unwanted outcomes in SESs suggests that this is common. In 
contrast to classical management techniques, a resilience-centered approach to management makes the following assumptions:

1. SESs may contain thresholds and can exhibit hysteretic and irreversible changes. Resilience assessment focuses upon identifying and understanding the processes that produce these thresholds. Therefore, in contrast to the assumption underlying many economics-based models for natural systems and using their terminology, social-ecological systems are not convex. Marginal outputs from processes in which ecosystem services are inputs may not decrease smoothly as output is increased. The existence of thresholds and hysteretic effects should be assumed.

2. Probability distributions for key decision variables are highly uncertain; both the functional form and parameters of distributions may be unknown. Improper priors (i.e., probability distributions whose integral is not unity) may dominate the analysis. Moreover, the key parameters may change faster than we can update information. Although work has been done on decision making under dynamic and unknown probabilities, most of the resulting decisions are extremely cautious, which is itself a form of rigidity that forestalls innovation and undermines resilience. Rather, we need some way to move forward despite vast uncertanties.

3. Decision makers in social-ecological systems must make decisions based on imperfect knowledge, with limited resources. Furthermore, decisions do not solely concern the consumption of goods and services. Agents often do not make income-maximizing decisions and the utility functions used to represent agent behavior must be sufficiently rich to include this. Utility depends upon social context. In economics terminology, agents are boundedly rational.

4. Market imperfections are the norm, not the exception, thus market-based valuations are usually distorted.

5. Agents hold preferences, not just over outcomes (consumption bundles), but over the social, economic, and political processes that govern those outcomes (Pritchard et al. 2000). Most stakeholders are not content to be represented in the process by a mere abstract utility function. Expert solutions may maximize something, but they rarely maximize legitimacy.

6. Well-defined property rights do not exist for many important ecological goods and services and, therefore, markets do not exist.

Where these six assumptions hold, the many management techniques that depend on the fact they do not hold have much reduced value. For a resilience analysis, we need a process that stimulates creative thinking about the future and allows both stakeholders (as an integral component of the SES) and researchers to compare maps of various pathways to the future. Pathways that are robust to ambiguous and unforeseeable changes suggest actions that can be taken to increase the resilience of a given SES. The challenge, then, is to understand the biophysical and social components of resilience and bring them to the consideration of voters, interest groups, and politicians. Therefore, we also offer resilience analysis and management as an approach that is better attuned than optimal command-and-control solutions to the conflicting objectives and complexity of a pluralistic modern society.

How can resilient pathways be discovered? We are testing a provisional procedure that consists of four steps. Some aspects of the approach borrow from the adaptive management approach developed by Holling (1978) and Walters (1986) and others borrow from ideas of scenario planning (van der Heijden 1996). The four steps are as follows. First, representatives of stakeholder groups are involved in establishing the important attributes of the study system and the range of possible trajectories that the stakeholders might try to make this system follow (steps 1 and 2). This information is then used for more specialized, quantitative analyses of where resilience resides (step 3). Finally, an integrated evaluation of management and policy implications is developed with input from both scientists and stakeholders (step 4). Defining the problem at the start involves identifying the critical, necessary stakeholders. Without their participation, achieving a collectively and socially desirable outcome is not possible, because key information resides in the knowledge and mental models of stakeholders, and because, without the inclusion that comes from participatory approaches, any proposed solution would face a legitimacy problem. Identifying this 
group, in turn, requires knowledge of the institutional framework that determines the rules for ecosystem use, with particular reference to property or usage rights and the locus of decisions. Ostrom (1999) has developed a detailed coding manual designed to elicit this information from stakeholders. We assert that a successful outcome of any procedure aimed at achieving social-ecological sustainability is fundamentally dependent on the active, positive involvement of all relevant stakeholders. Development of sound guidelines for making the framework operational is not a trivial task and needs to follow the experiences and results of the process in a number of different SESs. Here, we deal with what needs to be achieved in each of the steps. We welcome comments and improvements to it, as the framework will surely change as it develops further.

In the remainder of the paper, we outline an approach to working with stakeholders to explore possible management or governance regimes based on the concept of resilience. In order to set the stage, we give a brief review of the development of the resilience concept as it emerged from the study of ecological systems and was subsequently applied to SESs. With the development of the idea of resilience has come some terminology that must be carefully defined. First, therefore, we clarify the terminology and then present some background to describe the approach in practice.

\section{Terminology}

The literature on systems dynamics is bedeviled with loose terminology and multiple definitions. We concur with the assessment of Grimm et al. (1992), and their checklist of features to be considered in discussing stability concepts in a particular situation. A more detailed account of our interpretation is given in Carpenter et al. (2001). To minimize confusion in what follows it is necessary to clarify here our use of the terms "state" and "resilience."

The "state" of a system at a particular instant in time is the collection of values of the state variables at that time. The term is often used without reference to its fundamental dependence on time. In complex systems whose description requires many state variables, the term "state" is loosely used to describe a characteristic of the system, rather than its state. For example, the lake is in a eutrophic "state", or the rangeland is in a shrub-dominated "state." Such a loose definition is acceptable in everyday situations, but not when we want to analyze a system more carefully (cf. Grimm et al. 1992).

Often what we describe as a state in a dynamical system is actually a collection of states, the mathematical expression for which is an attractor. That is, the system visits the same states over and over again. The system may be stochastic, in which case future states are drawn from the same probability distribution, or sequence of probability distributions. In the case of a social-ecological system, we are usually interested in preserving a particular set of general criteria. The system can be in many different states and still meet this set of criteria. It does not make sense to describe a system that meets these criteria as being in a desirable "state" and we adopt the term "configuration" to describe a collection of states (usually an attractor or attractors, which may be stochastic) that meet a certain set of criteria. It then makes sense to refer to a system as being in a desirable or undesirable configuration (i.e., the behavior of the system is confined to a collection of (usually infinitely many) states that, taken together, produce a desirable or undesirable outcome.

The terms "resilience" and "adaptive capacity" are sometimes used interchangeably. For resilience, we adopt Holling's (1973) original meaning, as opposed to the notion of "engineering resilience" (Holling 1996); in this sense, resilience has three defining characteristics:

- The amount of change a system can undergo (and, therefore, the amount of stress it can sustain) and still retain the same controls on function and structure (still be in the same configurationwithin the same domain of attraction).

- The degree to which the system is capable of selforganization. When managers control certain variables in a system, they create inter-variable feedbacks that would not be there without their intervention. The more "self-organizing" the system, the fewer feedbacks need to be introduced by managers. Furthermore, if the system is strongly self-organizing, those feedbacks that do need to be built in by managers are not "delicate" or "sensitive," in that there can be significant error in the feedback induced by the manager without the system deviating from the desired behavior. (Note that, in this discussion of management, 
managers could be regarded as being either "in" or "out" of the system. We regard them as being "in," or as part of the system).

- The degree to which the system expresses capacity for learning and adaptation.

Resilience, therefore, is the potential of a system to remain in a particular configuration and to maintain its feedbacks and functions, and involves the ability of the system to reorganize following disturbancedriven change. In an operational sense, resilience needs to be considered in a specific context. As discussed by Carpenter et al. (2001), it requires defining the resilience of what to what?

Adaptive capacity is an aspect of resilience that reflects learning, flexibility to experiment and adopt novel solutions, and development of generalized responses to broad classes of challenges. Can SESs become generally resilient to a range of disturbances, including novel conditions? It is this type of behavior that we regard as being the adaptive capacity of a system. We recognize that the definition of adaptive capacity is relatively vague and requires further development. Despite this vagueness, it is useful to have a term for a broad class of flexible learning responses, which often turn out to be crucial when an SES is exposed to completely novel challenges.

Resilience is not necessarily desirable. System configurations that decrease social welfare, such as polluted water supplies or dictatorships, can be highly resistant to change. Some (social) systems may be resistant, yet not resilient (i.e., they do not allow for self-organization and learning), but some undesired ecological configurations may indeed be both resistant and resilient. Sustainability, in contrast, is an overarching goal that generally includes assumptions or preferences about which system configurations are desirable. Building resilience of a desired system configuration requires enhancing the structures and processes (social, ecological, economic) that enable it to reorganize following a disturbance. It also requires reducing those that tend to undermine it.

\section{Background}

As a metaphor to guide the case studies, we employ the adaptive cycle (Holling 1986, Gunderson and Holling 2002). Managed systems show a tendency to repeat characteristic behavioral phases and it is useful to identify them because different management and policy interventions are appropriate in different phases (Carpenter and Gunderson 2001). The adaptive cycle involves the movement of a system through four phases: a period of rapid growth and exploitation (r); leading into a long phase of accumulation, monopolization, and conservation of structure, during which resilience tends to decline $(\mathrm{K})$; a very rapid breakdown or release phase (creative destruction $(\Omega)$ ); and, finally, a relatively short phase of renewal and reorganization $(\alpha)$. If, in this phase, the system still retains sufficient of its previous components it can reorganize to remain within the same configuration as before. But it is also a time when novelty can enter-new species, new institutions, ideas, policies, and industries - and the "new", emerging system, whether it is in the same or a different configuration, gains resilience. A full description, with examples, is given in Holling (2001) and Gunderson and Holling (2002). We use this metaphor as a guide to thinking about SES dynamics because it emphasizes the importance of changes in resilience and focuses on the timing of management interventions.

The "forward" ( $\mathrm{r}$ to K) and "backloop" ( $\Omega$ to $\alpha$ ) dynamics of the adaptive cycle correspond to managing for production and managing for sustainability: Both are important objectives. They can be likened, in the area of investment, to the part of the portfolio aimed at maximizing income $(\mathrm{r}-\mathrm{K})$ and the part aimed at maximizing flexibility to cope with, and adapt to, unexpected change in the market $(\Omega$ to $\alpha$ ). Just as there are costs and benefits involved in diversifying an investment portfolio, so there are costs and benefits involved in building resilience and we need to understand the trade-offs and synergies between production and resilience. Achieving both objectives needs a clear understanding of when it is appropriate to try to increase production efficiency, and when (and where) it is appropriate to try to ensure sustainability, summarized as follows.

$r$ to K: Strong controls, the system changes slowly; regulatory policies and efforts to increase efficiency may be appropriate, although careful experimentation is sometimes critical; application of techniques such as optimal control can be useful. However, resilience can be lost through gradual changes in underlying slow variables. 
$\Omega$ to $\alpha$ : The system changes rapidly, no equilibria, turbulent, novelty can enter. What is the appropriate approach to research and management? How can creative and potentially resilient new practices be discovered? The system is susceptible to loss of resources (soil erosion, species, human and financial capital) and measures to conserve capital are appropriate. It is also vulnerable to entering a potentially undesirable configuration. Guidance is needed. Influential ideas ("good" and "bad") can become entrenched and guide subsequent evolution of the system.

A regional SES does not consist of just one kind of cycle at one scale. It functions as a nested, hierarchical structure, with processes clustered within subsystems at several scales (farm, catchment, state, for example). Different subsystems, at different scales, may be in different phases and may change at different rates (Gunderson and Holling 2002). The subsystems are semiautonomous, but cross-scale interactions do occur. Particular attention needs to be paid to these crossscale interactions during the assessment phase in the framework that follows.

In the 150 years since it was fully settled, the Goulburn-Broken Valley in Australia (presented later in Fig. 2) has undergone four periods of major changes (equating to the backloop dynamics), over a total of 20 to 25 years - a maximum of about $15 \%$ of the time. This may be typical for regional SESs. Because they spend by far the majority of their time in the $\mathrm{r}-\mathrm{K}$ phases, almost all research and development has been devoted to $r-K$ kinds of dynamics. Very little attention has been given to understanding and managing systems going through periods of turbulent, transformational change. The framework in this paper presents an approach for investigating how the metaphorical dynamics just described actually work in practice, in particular regions.

\section{RESILIENCE MANAGEMENT}

The twin aims of resilience management are:

- To prevent the system from moving to undesired system configurations in the face of external stresses and disturbance. This might include enhancing resistance (reducing the amount the system will change in response to a given amount of stress). In a ball-and-cup metaphor of system dynamics, this is equivalent to deepening the cup in which we want the ball to remain. However, although increasing resistance increases the amount of external force required to change the system in the short term, policies that make SESs more rigid often have reduced resilience (Gunderson et al. 1995). The desired outcome of resilience analysis is actions that will restore lost resilience, or enhance it to allow a greater array of "safe" resource-use options. In a ball-and-cup metaphor, this is equivalent to broadening the diameter of the cup. This is different from guiding the system toward a target on the basis of forecasts. Instead, we attempt to strengthen the feedbacks that tend to maintain a particular desired configuration. Where an SES is already in an undesirable configuration, resilience management involves reducing the resilience of this configuration as well as enhancing the resilience of desired ones.

- To nurture and preserve the elements that enable the system to renew and reorganize itself following a massive change. This adaptive capacity resides in aspects of memory, creativity, innovation, flexibility, and diversity of ecological components and human capabilities.

\section{THE FRAMEWORK}

A summary of the proposed framework for analyzing social-ecological resilience is presented in Fig. 1.

\section{Step 1. Resilience of what?}

The first step is the development of a conceptual model of the SES, based strongly on stakeholder inputs. It bounds the problem and elicits information on the important issues in the SES and the major drivers. The process serves as a vehicle to define the system and to use what is known to identify the areas of uncertainty about the system's dynamics. By attempting what we have asserted is not possible-a forecast of the future of the system if current management continues-we expose uncertainties. The actual procedure will vary from region to region, depending on the levels of knowledge, 
Fig. 1. A framework for the analysis of resilience in social-ecological systems.

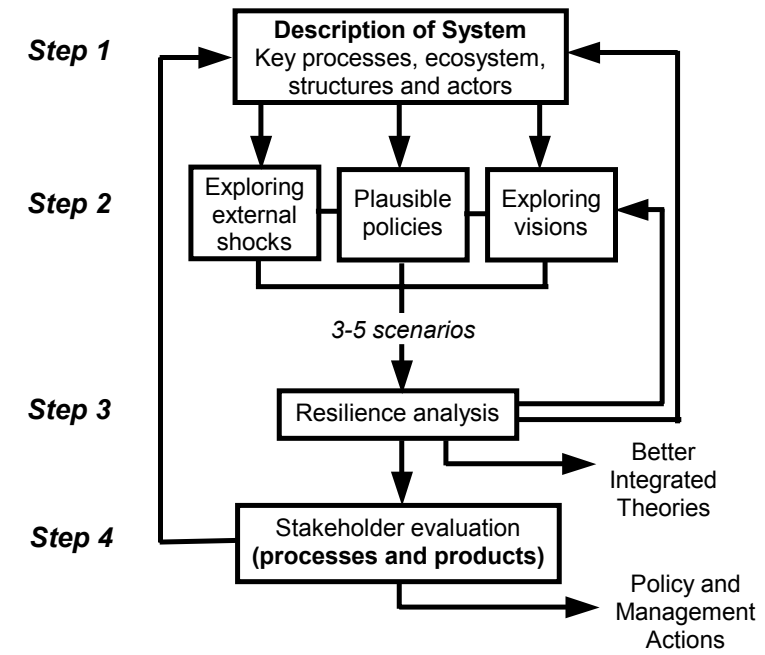

experience, and expertise available, but it will address specific questions such as:

- What are the spatial boundaries of the SES?

- What are the key ecosystem services used by, and of concern to, people in the SES? What do they value?

- Who are the stakeholders?

- What are the key components of the SES, what are the natures and significance of their spatial patterns, what are their turnover times, and to what extent are their dynamics endogenous vs. influenced by exchange across the boundaries of the SES?

- What is the historical profile of the system? How did it get to be what it is now-what changes occurred through its history in terms of ecosystem, technology, society, economy, and so forth? Careful analysis of historical profiles reveals a great deal about current system dynamics and how the system might respond to future external shocks. We have found it useful to develop the historical profile at three scales (local, regional, and multi-regional) and then look for cross-scale effects. The local scale deals with changes that have occurred at the scale of an ecological patch up to the property level. The regional scale is defined by the study area being considered. All kinds of changes (ecological, technological, economic, social) are considered at all three scales. From a recent workshop in the Goulburn-Broken Valley in Australia, where the participants preferred to work using just one time line, it appeared that over the past 150 years the region had experienced four periods when major changes occurred, leading to new trajectories. It is presented here as an example (Fig. 2).

- What are the important, controlling variables that act as drivers of the key ecosystem goods and services people want? The crucial driving variables tend to have slower dynamics than the ecosystem goods and services they control, and the two types will be referred to as "slow" and "fast" variables (Carpenter and Turner 2000).

- Which factors are controllable (e.g., land use policy) and which are not (e.g., climate)? What are the ambiguities in the system, the uncertainties that can be neither controlled nor quantified?

- How do the current institutional arrangements, property rights in particular, and the distribution of power and wealth influence formal and informal decision making and access to information?

The product of step 1 is a conceptual model embodying what is known about the system in terms of issues deemed important to the stakeholders, and what determines them. It provides an essential heuristic basis for step 2 and (very importantly) it defines the "of what" part of the resilience analysis (Carpenter et al. 2001). Being clear and explicit about just which ecosystem services or variables are of concern is a necessary first step in the analysis (that is, it is essential to define the resilience "of what" system configurations we are interested in studying (Binning et al. 2001)).

\section{Step 2. Resilience to what? Visions and scenarios}

Step 2 examines the external disturbances and the development processes (policy drivers and stakeholder actions) to which the desirable configurations are expected to be resilient. Its aim is 
Fig. 2. Historical profile of major events and developments in the Goulburn-Broken catchment. The periods with " ? $Q$ " denote times of major events or crisis, followed by reorganization.

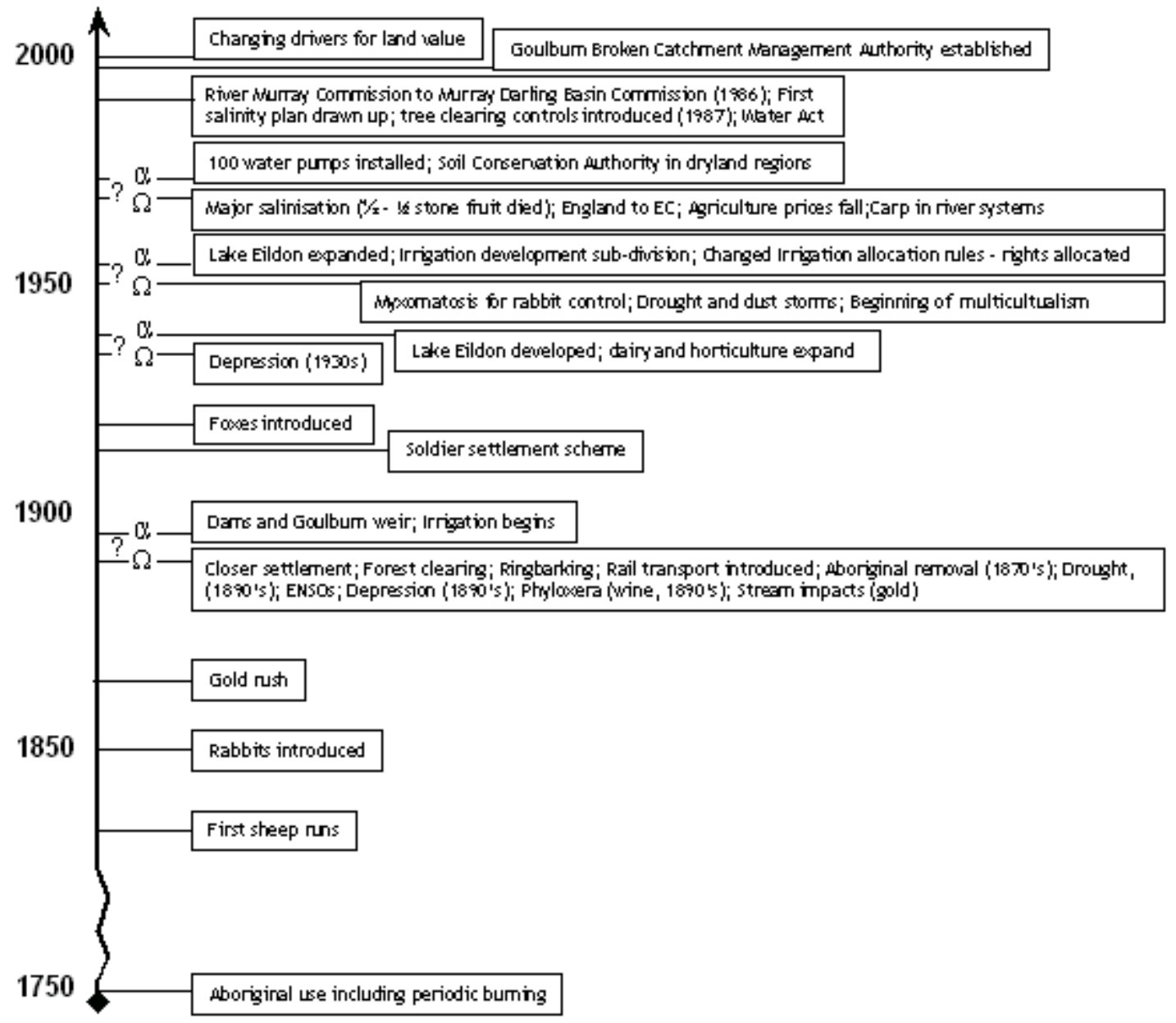

develop a limited set of possible future scenarios that includes the outcome of uncontrollable and ambiguous external drivers. The term "scenario" has more than one meaning. We define a scenario as a plausible exploration of the future, to be used in combination with other scenarios to explore the robustness of diverse models and choices (Wack 1985a, b, van der Heijden 1996, Carpenter 2002). We are especially interested in the role of scenarios in formulating responses to unexpected events (e.g., Wack $1985 a, b)$ and this is the way we use them here: as a means of confronting stakeholders with possible surprises.

With or without deliberate planning, the stakeholders in the system will attempt to drive it along one or more trajectories. Visions about preferred directions will differ among stakeholder groups and the actual trajectory the system follows will be the outcome of stakeholder interactions and external drivers. The first priority in step 2, therefore, is to establish a range of possible trajectories; at least a business-as-usual one plus, for example, a more conservative one and a more developmental or growth-oriented one. These visions are built into the scenarios used to examine resilience.

The scenarios need to span a broad range of possible outcomes. Experience with scenarios in diverse decision environments indicates that teams can process at most about three to five (van der Heijden 1996). We anticipate that the group may initially develop a rather large set of potential scenarios, and 
then condense this into a manageable few that capture the most important uncertainties spanning the range of conditions the system might have to face, as well as the visions people have for their future. For example, scenarios for a river basin might include unusually wet or dry climate, unexpectedly large population growth due to environmental refugees from a neighboring region, and technological innovations leading to a massive increase in efficiency of irrigation. The scenarios, therefore, represent a range of outcomes for ambiguous and uncontrollable factors that can be generally agreed upon, and that are the ultimate drivers of the system variables. Although scenarios are not value free, they are consistent with all available information (including biophysical laws) and represent a consensus view of a range of possible outcomes that stakeholders need to consider. They should identify the most important ambiguities for the future of the SES (external influences that the SES cannot influence but may have to cope with). We define ambiguities as uncertainties that cannot be assigned a probability distribution (although it may be possible to bound them using physical laws, such as conservation of matter or energy). Examples are variability resulting from climate change, technological innovation, and unforeseeable reactions of people to unfolding change in the social-ecological system.

The scenarios are developed by considering, in parallel, three different kinds of drivers of the socialecological system's future: external shocks and disturbances (physical, social, and economic); the visions, hopes, and fears that people have for the future; and a set of possible policies that might conceivably be imposed. The scenarios create a framework to discover pathways and actions that connect the kinds of worlds people prefer (or seek to avoid) with the kinds of drivers to which they will have to adapt as they strive to attain their visions. Policies are the rules that guide the trajectories of the SES. Note that policies arise in many forms and at many levels. For example, we may be concerned with broad, overarching policy goals, general strategies for achieving these goals, or specific policy instruments designed to manipulate an SES in a particular way. Referring back to the discussion on adaptive cycles, some policies will influence the general adaptive capacity of the system and others will control the dynamics of the system in regard to particular state variables. The aim of the next step in the approach, therefore, is to develop ways of examining the dynamics of the SES under the range of conditions encompassed by the scenarios, concentrating on resilience.

Scenarios are of particular interest because of the role that perceptions of attainable futures play in creating the future. If you don't know where you want to go, it doesn't matter which road you take (to paraphrase the Cheshire cat in Alice in Wonderland). The forward-looking capacity of people is crucial to the evolving organization of the SES and the resilience of the trajectory that the SES will eventually follow.

\section{Step 3. Resilience analysis}

Steps 1 and 2 generate two sets of information: major issues about future states of the system that are of concern to stakeholders, and major uncertainties about how the system will respond to drivers of change. Step 3 consists of exploring the interactions of these two sets through a combination of modeling and non-modeling methods. The aim is to identify possible driving variables and processes in the system that govern the dynamics of those variables stakeholders deem to be important (the ecosystem goods and services), looking especially for threshold effects and other non-linearities. The process of discovery is necessarily iterative and begins with discussions among stakeholders, policy makers, other local experts, and scientists aimed at examining how the system will respond and change under the various scenarios so as to identify possible groups of interacting variables where non-linearities are likely. In fact, these discussions in themselves will go a long way towards building a common understanding of resilient pathways.

Understanding is next advanced through the development of a number of simple models of the system's dynamics, highlighting the significance of variables operating at different time scales, and focusing especially on the underlying driving variables and non-linearities. Examples of the sorts of models and analysis are given in the next section. Analyses and gaming exercises with the models, using the scenarios to set parameter values (or to introduce or redefine parameters), will be used to explore pathways to alternative futures and to identify attributes of the SES that affect resilience. Prototypes of such models are found in Carpenter et al. (1999a, b) and Janssen et al. (2000), but we do not restrict the process to any particular type of 
models. In this context, a model is any representation (art, writing, music, or mathematics, for example) that allows people to manipulate or understand abstractions (Root-Bernstein and RootBernstein 1999).

An important feature that must be included in these modeling and other exercises is the reflexive behavior of people in respect to their use of ecosystems, and this is drawn out in second-round discussions with stakeholders. These discussions need to include a focus on the social aspects of resilience (identifying, for example, how in this SES changes in the composition of any of the six functional groups of people proposed by Berkes and Folke (in press) may or may not be retracting from resilience). In regard to the modeling exercises, it is at this stage that more data may need to be collected. A key aim of resilience analysis is to identify thresholds, their nature, and what determines their positions along the driving variables. It may be possible to use plausible ranges of parameter values for the models and thus get a sufficiently good understanding of policy implications, but it is likely that for some key processes and response curves new data will be needed.

It is difficult to describe step 3 more precisely, because it is context dependent and each SES will require a different combination and balance of models and non-modeling analyses. If successful, it will merge with step 4 and, through revisions and the introduction of new models, be a continuing part of the SES governance.

\section{Step 4. Resilience management (evaluation and implications)}

The final step involves a stakeholder evaluation of the whole process and the implications of the emerging understanding for policy and management actions. As described in the examples that follow, a successful resilience analysis identifies the processes that determine critical levels of the system's important control variables. This set of processes leads to a corresponding set of actions that can enhance or reduce resilience and that, therefore, form the basis for resilience management and policy. Cast in the language of optimal control, there is no attempt to keep the system on some predicted, optimal path. Rather, the policies are aimed at a set of rules (incentives and disincentives) that enhance the system's ability to reorganize and move within some configuration of acceptable states, without knowing or caring which particular path the system might follow. Only through a shared understanding among the different stakeholder groups of the processes and of their implications for the system, will changes in policy and management actually arise. There is no guarantee, of course, that such a shared understanding leading to sustainable outcomes will be achieved, either because of intractable ecological issues or intractable social issues. Our experience to date suggests the latter might be the more difficult to resolve, but the chances of success are increased if the full range of stakeholders is engaged.

\section{STYLIZED EXAMPLES OF RESILIENCE ANALYSIS}

The desired outcome of resilience analysis is a set of targets for policy and management that will achieve sustainability (continued well-being of the economy, society, and the natural resource base). The outcome we seek, therefore, is a set of actions that will maintain or enhance resilience of the desired (or at least acceptable) set of trajectories. We use a stylized example to illustrate step 3 in the SES assessment.

The level of supply of ecosystem services depends on the state that the system is in. In particular, where ecosystems exhibit threshold effects and multi-stable states, the supply of ecosystem services depends more on which configuration the ecosystem is in than on the particular combination of the state variables (see Carpenter 2001 and Scheffer et al. 2001 for examples of threshold effects). There are many particular states (combinations of state variables) that will provide the desired supply of ecosystem services. Thus, the important thing is not to try to maximize the supply by aiming for a particular state, but rather to remain within the system configuration into which these desirable (acceptable) states fall. Fig. 3 illustrates this for two examples of systems dominated by single-state variables. 
Fig. 3. Supply of ecosystem services as a function of ecosystem state. 'A' represents rangeland ecosystem services (wool production from grazing) as a function of woody vegetation biomass (W). 'B' represents lake ecosystem services (fish, recreation) in Wisconsin as a function of $\mathrm{P}$ in lake sediment and agricultural soil in the catchment. $\mathrm{Vc}$ is the critical threshold level of $\mathrm{P}$ and $\mathrm{W}$, demarcating a flip from one stability domain to another.

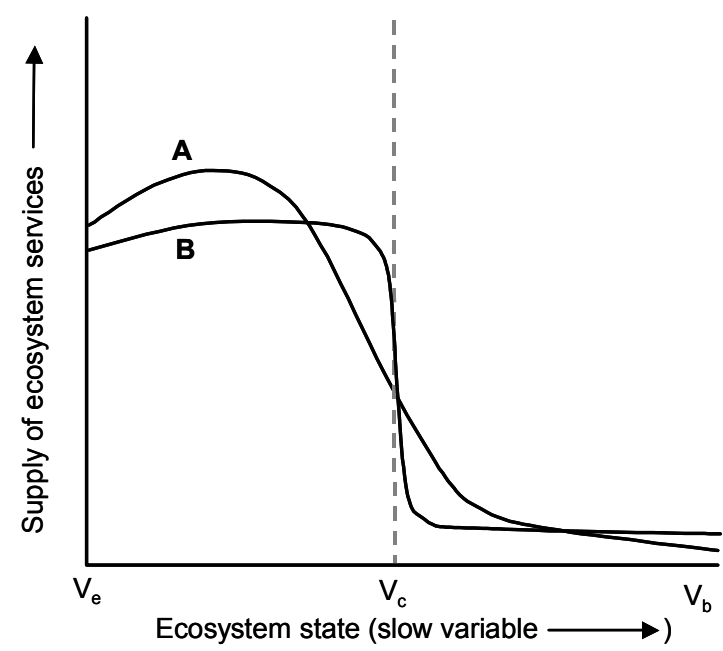

In two examples of this effect, the shallow lakes of Europe and the agriculture-lake system of Wisconsin (Carpenter et al. 1999a, b, Scheffer et al. 2000), the supply of lake goods and services (i.e., desirable fish and aesthetic water condition) is determined by phosphate $(\mathrm{P})$ in catchment soils and lake sediments. As long as this level remains below a critical threshold, $\mathrm{Vc}$, the amount of $\mathrm{P}$ in the water (on the $\mathrm{Y}$ axis in Fig. 3) is controllable by lake ecosystem processes and the supply of services remains high. The relationship between ecosystem services and the amount of $\mathrm{P}$ in the water, therefore, approximates a step function (B in Fig. 3). In rangelands subject to woody weed invasion, $\mathrm{V}$ in Fig. 3 equates to the cover of woody plants (Perrings and Walker 1995, Anderies et al. 2002). The supply of ecosystem services (livestock products) depends on the amount of grass, which in turn depends on the amount of shrub cover (W). Above the critical threshold of W $(\mathrm{Vc})$, there may be insufficient grass, even in the absence of grazing, to carry a fire that will control shrubs. In both cases, allowing $\mathrm{V}$ to increase beyond $\mathrm{Vc}$ results in a change in configuration. In terms of sustainability and the dynamics of the adaptive cycle, it means that the system has moved into a new, undesirable trajectory. Given the consequences of this, it is more important to keep the system in the desired configuration of states than it is to try to achieve some particular state that maximizes the supply of ecosystem services.

If we now expand our view to a total, linked SES, we need to know the set of V's (in the ecosystem, the social system, and the economic system) that constitute the crucial driving variables that determine the underlying dynamics of the SES through time. Fig. 4 extends the rangeland example from Fig. 3 to a two-variable depiction of such a multi-dimensional system. It illustrates hypothetical trajectories through the state space comprising one economic driving variable (debt to income ratio, $\mathrm{Vcl}$ in Fig. 4) and one ecological variable (W from Fig. 3, Vc2 in Fig. 4).

To be sustainable, the objective is to stay in box A, as illustrated in Fig. 4i, preferably at least cost. To maintain high levels of ecosystem services, desirable trajectories will remain below the critical level of W. This amount can be exceeded, regardless of the level of debt to income ratio, through lack of ecological understanding or through short-term profit seeking. However, if the trajectory moves into box B (Fig. 4ii), the region that is still below the $\mathrm{W}$ threshold but above the debt:income threshold, the farmer will likely be forced to graze too heavily in order to service his debt and the system will then move to the right and down as the farmer increases grazing pressure in an attempt to reduce debt. Depending on the options open to the farmer, and his or her capacity to adapt and do different things, the position of the debt:income threshold could be moved upwards and the system could remain in a sustainable configuration. The ability to access alternative, off-farm income can do just this. The ability to change from livestock production to a nonconsumptive use of wildlife (e.g., Cumming 1993) would do the same. But if adaptive capacity is limited, the system behaves as in this example and crosses the woody threshold before regaining a sustainable debt to income ratio. Therefore, it moves into the even less desirable upper right-hand part of the state space (box D). Similarly, starting in the desirable configuration $\mathrm{A}$, if the system moves into $\mathrm{C}$ (Fig. 4ii), the decline in the flow of ecosystem goods and services will have a negative effect on income, reducing capacity to service debt, and likely cause the system to move into $\mathrm{D}$, with very few options for recovery. 
Fig. 4. Possible trajectories of a 2 -variable system through time. The positions of the dashed lines on the axes represent critical threshold levels of the sort depicted in Fig 3. See text for explanation.

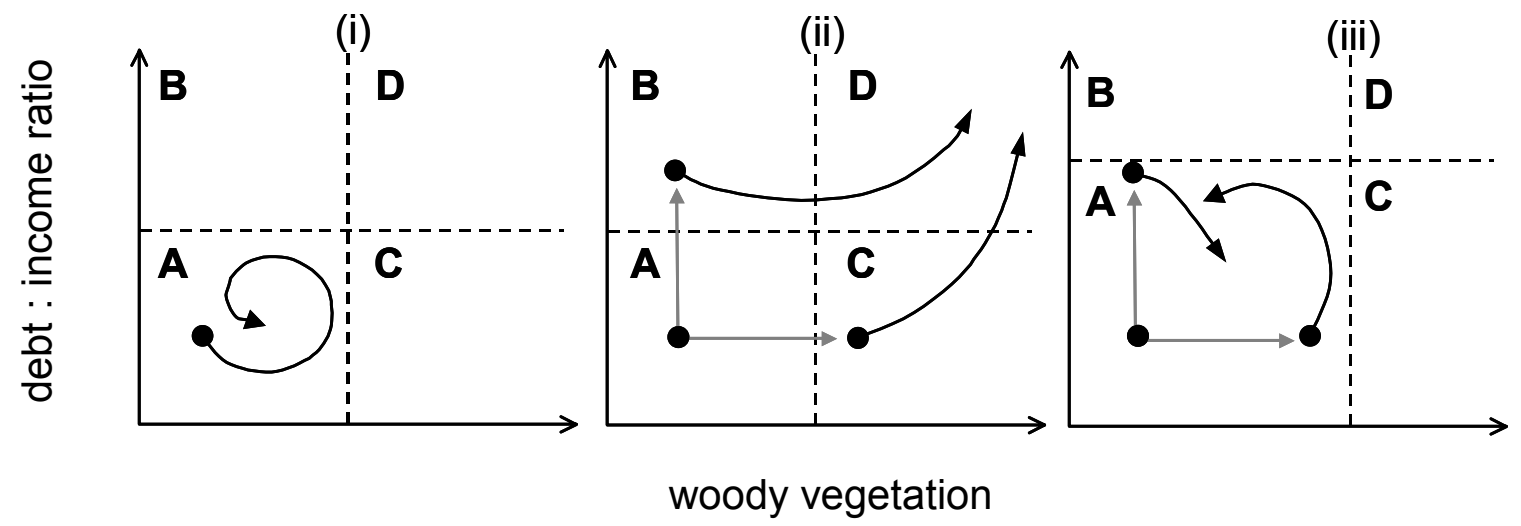

This example, with the possibility that a farmer can adapt by doing different things and avoid exceeding a biophysical resilience threshold, raises the earlier discussion of resilience vs. adaptive capacity. Resilience applies to the dynamics of a defined system. Adaptive capacity can apply to the same defined system, but adaptations that bring in new variables effectively redefine the system. The developing model of the system, with regard to resilience management, needs to be able to take such system changes into account. As discussed earlier, this is an extension of the adaptive management approach developed by Holling (1973) and Walters (1986). One aspect of the extension concerns the inclusion of the stakeholders as integral components of the system, and their behavior as drivers of the system's trajectory (cf. Magee et al. 1989). Resilience management in this sense includes adaptations that redefine the system to avoid exceeding resilience boundaries.

The further the system moves to the upper right part of the state space, the greater the external input that is required to get it back into the sustainable space. Perturbations can drive the system out of A into either $\mathrm{C}$ or $\mathrm{D}$, after which the inter-linked nature of the dynamics of an SES tends to drive it into D. A crucial part of resilience analysis is understanding the way in which the system responds to this combination of perturbations and underlying dynamics. Once in $\mathrm{C}$ or $\mathrm{B}$, it may be very difficult to get back to $\mathrm{A}$, and the best policy or management action, therefore, is to increase the size of A (Fig. 4iii). In the rangeland example, one way to increase the size of A along the biophysical axis is to increase the proportion of perennial species in the grass sward, and increasing the socio-economic side of A might be achieved by increasing access to alternative (external) sources of income.

This example relates to a particular rangeland system or property. Over an entire rangeland region, we can envisage all the properties, or otherwise defined rangeland systems, as a cloud of points located somewhere in this phase space. The entire cloud might be in box A, but it is likely that, in most rangeland regions, there will be some points in all of the boxes, and the aims of policy based on resilience would be to try 1) to prevent the cloud from shifting to the upper right, 2) to move the cloud back down in the lower left direction, and 3) to increase the size of box A so as to encompass most of the cloud. The policies influencing interactions among individual farmers will strongly influence the size and shape of the cloud and, therefore, the regional SES trajectory.

This hypothetical example identifies two sets of information needed to assess resilience in an SES:

1. The set of crucial (slow) variables that collectively determines the dynamic behavior of the system and that, therefore, governs the supply of ecosystem services.

2. The processes that drive the dynamics of this set of crucial variables. In particular, what determines the positions of thresholds along these variables? For instance, for the lakes 
system described earlier, two such "parameters" are the amounts and condition of riparian vegetation and wetlands, both of which trap phosphates and reduce the amount of $\mathrm{P}$ entering the lake (and, therefore, the sediment). For the rangeland example, the parameters are grazing pressure (livestock numbers), fire frequency, and diversity of perennial grass species. Examples of parameters controlling driving socio-economic variables are culture, traditional ecological knowledge, and property-rights systems (Berkes and Folke 1998, Hanna et al. 1996). In the rangeland example, although the ratio of debt to income may itself be changing quite slowly in response to various internal processes, the critical level of debt:income ratio can be suddenly and significantly changed through external factors such as a change in the interest or exchange rates. Such changes would constitute different scenarios in the analysis and the aim would be to discover what system attributes could be enhanced or reduced so that the system could become more resilient to these changes. Alternative sources of income could be one such attribute.

3. This list of processes controlling the driving variables, and the positions of the critical thresholds along these variables, constitutes the final step in the SES resilience assessment. It identifies, for the SES stakeholders, a corresponding catalogue of management and policy actions that will build adaptive capacity in the SES. Effecting these actions meets the twin aims of resilience management (preventing the system moving out of configuration $\mathrm{A}$ in Fig. 4, and increasing the size of A) and increases the long-term sustainability of the social-ecological system.

\section{CONCLUDING REMARKS}

In this paper, we have proposed that ecosystems provide a stream of goods and services that, depending on how they are managed, are subject to different risks of loss. Decreasing resilience in the system increases the risk of loss. Conventional management methods, such as the suite of decision analysis techniques, are appropriate for improving rates of return during slowly changing periods of growth and accumulation, although the consequence of increased efficiency of resource use in these times may be a concomitant loss of resilience. We propose that, during times of crisis, breakdown, and reorganization, managing to safeguard and build resilience is most important. The framework we have presented for analyzing resilience in regionalscale social-ecological systems is suggested as a basis for such management. It involves a stakeholder-driven description of the system and the issues, leading to a limited set of scenarios that capture the major uncertainties in the system's future dynamics. A variety of simple models and other means of describing the dynamics of the system are then used to work through the scenarios to identify the components of the system's resilience and, therefore, how resilience may be lost or enhanced.

The attempts to analyze resilience that resulted in this paper have highlighted a number of areas needing further research. Two in particular are worth noting. One concerns thresholds: how to discover their existence, especially if they have not yet been encountered, and what determines their locations along the variables concerned. We need to establish a typology of thresholds to help us know what kinds of thresholds in what kinds of systems we should be looking for. The other main research area is the evolution of rules in social-ecological systems. The rules that govern SES dynamics are not fixed. They evolve over time in response to both biophysical and social changes. Understanding how they evolve is crucial if we are to achieve policies that enable SESs to self-organize along acceptable trajectories.

Responses to this article can be read online at: http://www.consecol.org/Journal/vol6/iss1/art14/response s/index.html

Acknowledgments:

This work is funded through grants to the Resilience Alliance from the Rockefeller Foundation and the James S. MacDonnell Foundation, and other grants to the authors. We are indebted to many of our colleagues for discussions and ideas that are reflected throughout this paper. We are also indebted to two anonymous referees for critical and helpful comments that have much improved the paper.

\section{LITERATURE CITED}

Abel, N., M. Gachugu, A. Langston, D. Freudenberger, M. Howden, and S. Marsden. 2002. Policies, planning and institutions for sustainable resource use: a participatory approach. In A. C. Grice and K. C. 
Hodgkinson, editors. Global rangelands: progress and prospects. CAB International, Wallingford, UK.

Allen, T. F. H., and T. W. Hoekstra. 1992. Toward a unified ecology. Columbia University Press, New York, New York, USA.

Anderies, J. M., M. A. Janssen, and B. H. Walker. 2002. Grazing management, resilience and the dynamics of a fire driven rangeland system. Ecosystems 5:23-44.

Berkes, F., and C. Folke. 1998. Linking social and ecological systems: management practices and social mechanisms for building resilience. Cambridge University Press, Cambridge, UK.

Binning, C., S. Cork, R. Parry, and D. Shelton. 2001. Natural assets: an inventory of ecosystem goods and services in the Goulburn Broken Catchment. Report of the Ecosystem Services Project, CSIRO Sustainable Ecosystems, Canberra, Australia.

Bousquet, F., O. Barreteau, P. d'Aquino, M. Etienne, S. Boissau, S. Aubert, C. Le Page, D. Babin, and J. C. Castella. In press. Multi-agent systems and role games: an approach for ecosystem co-management. In M. A. Janssen, editor. Complexity and ecosystem management: the theory and practice of multi-agent systems. Edward Elgar Publishers, Cheltenham, UK/ Northampton, Massachussetts, USA.

Carpenter, S. R. 2001. Alternate states of ecosystems: Evidence and its implications. Pages 357-383 in M. C. Press, N. Huntly, and S. Levin, editors. Ecology: achievement and challenge. Blackwell, London, UK.

Carpenter, S. R. 2002. Ecological futures: building an ecology of the long now. Ecology, in press. (Online, URL: $\quad$ http://www.limnology.wisc.edu/macarthur/ ecofutures.pdf.)

Carpenter, S. R., W. A. Brock, and P. C. Hanson. 1999a. Ecological and social dynamics in simple models of ecosystem management. Conservation Ecology 3(2):4. (Online, URL: http://www.consecol.org/vol3/iss2/art4).

Carpenter, S. R., and L. H. Gunderson. 2001. Coping with collapse: ecological and social dynamics in ecosystem management. BioScience 51:451-457.

Carpenter, S. R., D. Ludwig, and W. A. Brock. 1999 b. Management of eutrophication for lakes subject to potentially irreversible change. Ecological Applications 9:751-771.

Carpenter, S. R., and M. G. Turner. 2000. Hares and tortoises: interactions of fast and slow variables in ecosystems. Ecosystems 3:495-497.
Carpenter, S. R., B. H. Walker, J. M. Anderies, and N. Abel. 2001. From metaphor to measurement: resilience of what to what? Ecosystems 4:765-781.

Checkland, P. B. 1981. Systems thinking, systems practice. John Wiley, New York, New York, USA.

Checkland, P., and J. Scholes. 1999. Soft systems methodology in action. John Wiley, New York, New York, USA.

Cocks, D. 1999. Future makers, future takers: life in Australia 2050. University of New South Wales Press, Sydney, Australia.

Cocks, D., and J. Ive 1996. Mediation support for forest land allocation: the SIRO-MED system. Environmental Management 20 (1):41-52.

Craig, W. J., T. M. Harris, and D. Weiner, editors. 2002. Community participation and geographic information systems. Taylor and Francis, London, UK.

Cumming, D. H. M. 1993. Multispecies systems: progress, prospects and challenges in sustaining range animal production and biodiversity in East and southern Africa. Pages 145-159 in Proceedings, VII World Conference on Animal Production, Edmonton, Alberta. Vol. 1, Invited Papers. Canadian Society of Animal Science, University of Alberta.

Folke, C., F. Berkes, and J. Colding. 1998. Ecological practices and social mechanisms for building resilience and sustainability. Pages 414-436 in F. Berkes and C. Folke. Linking social and ecological systems. Cambridge University Press, London, UK.

Grimm, V., E. Schmidt, and C. Wissel. 1992. On the application of stability concepts in ecology. Ecological Modelling 63:143-161.

Gunderson, L., and C. S. Holling, editors. 2002. Panarchy: understanding transformations in human and natural systems. Island Press, Washington, D. C., USA.

Gunderson, L., C. S. Holling, and S. S. Light. 1995. Barriers and bridges to the renewal of ecosystems and institutions. Columbia University Press, New York, New York, USA.

Hanna, S. S., C. Folke, and K.-G. Mäler. 1996. Rights to nature. Island Press, Washington, D. C., USA.

Holling, C. S. 1973. Resilience and stability of ecological systems. Annual Review of Ecology and Systematics 4:123. 
Holling, C. S., editor. 1978. Adaptive environmental assessment and management. John Wiley, New York, USA.

Holling, C. S. 1986. The resilience of terrestrial ecosystems: local surprise and global change. Pages 292317 in W. C. Clarkand and R. E. Munn, editors. Sustainable development of the biosphere. Cambridge University Press, Cambridge, UK.

Holling, C. S. 1987. Simplifying the complex: the paradigms of ecological function and structure. European Journal of Operational Research 30:139-146.

Holling, C. S. 1992. Cross-scale morphology, geometry and dynamics of ecosystems. Ecological Monographs 62:447-502.

Holling, C. S. 1995. What barriers? What bridges? Pages 3-34 in L. H. Gunderson, C. S. Holling, and S. S. Light, editors. Barriers and bridges to the renewal of ecosystems and institutions. Columbia University Press, New York, New York, USA.

Holling, C. S. 1996. Engineering resilience versus ecological resilience. Pages 31-44 in P. Schulze, editor. Engineering within ecological constraints. National Academy, Washington, D. C., USA.

Holling, C. S. 2001. Understanding the complexity of economic, ecological and social systems. Ecosystems 4:390-405.

Janssen, M. A., B. H. Walker, J. Langridge, and N. Abel. 2000. An adaptive agent model for analysing coevolution of management and policies in a complex rangeland system. Ecological Modelling 131:249-268.

Kay, J., H. Regier, M. Boyle, and G. Francis. 1999. An ecosystem approach for sustainability: addressing the challenge of complexity. Futures 31(7):721-742.

Kinzig, A., and 43 coauthors. 2000. Nature and society: an imperative for integrated environmental research. [Online, URL: http://lsweb.la.asu.edu/akinzig/report.htm.]

Krugman, P. 2000. The return of depression economics. Norton, New York, New York, USA.

Levin, S. A. 1999. Fragile dominion. Addison-Wesley, Reading, Massachusetts, USA.

Lowenstein, R. 2000. When genius failed: the rise and fall of long-term capital management. Random House, New York, New York, USA.
Magee, S. P., W. A. Brock, and L. Young. 1989. Black hole tariffs and endogenous policy theory. Cambridge University Press, Cambridge, UK.

Ostrom, E. 1999. Coping with tragedies of the commons. Annual Review of Political Science 2:493-535.

Perrings, C., and B. Walker. 1995. Biodiversity loss and the economics of discontinuous change in semiarid rangelands. Pages 190-210 in C. Perrings, K.-G. Maler, C. Folke, C. S. Holling, and B.-O. Jansson, editors. Biodiversity loss. Cambridge University Press, Cambridge, UK.

Peterson, G. D. 2000. Political ecology and ecological resilience: an integration of human and ecological dynamics. Ecological Economics 35:323-336.

Pretty J. N., I. Guijt, I. Scoones, and J. Thompson. 1995. A trainer's guide for participatory learning and action. IIED, London, UK.

Pritchard, L. Jr., C. Folke, and L. H. Gunderson. 2000. Valuation of ecosystem services in institutional context. Ecosystems 3:36-40.

Root-Bernstein, R., and M. Root-Bernstein. 1999. Sparks of genius. Houghton-Mifflin, New York, New York, USA.

Senge P. 1990. The fifth discipline: the art and practice of the learning organization. Doubleday, New York, New York, USA.

Scheffer, M., W. A. Brock, and F. Westley. 2000. Mechanisms preventing optimum use of ecosystem services: an interdisciplinary theoretical analysis. Ecosystems 3:451-471.

Scheffer, M., S. Carpenter, J. Foley, C. Folke, and B. Walker. 2001. Catastrophic regime shifts in ecosystems. Nature 413:591-596.

Slocum, R., L. Wichart, D. Rocheleau, and B. ThomasSlayter, editors. 1995. Power, process and participation: tools for change. Intermediate Technology Publications. Exter, UK.

Toth, F. L. 1988. Policy exercises. Simulation \& Games 19:235-276

van de Kerkhof, M. 2001. A survey on the methodology of participatory integrated assessment. IIASA Working paper IR-01-014, Laxenburg, Austria.

van der Heijden, K. 1996. Scenarios: the art of strategic conversation. John Wiley, New York, New York, USA. 
van den Hove, S. 2000. Participatory approaches to environmental policy-making: the European Commission Climate Policy Process as a case study. Ecological Economics 33(3):457-472.

Wack, P. 1985a. Scenarios-shooting the rapids. Harvard Business Review 63:139-150.

Wack, P. 1985b. Scenarios-uncharted waters ahead. Harvard Business Review 63:72-89.

Walters, C. 1986. Adaptive management of renewable resources. MacMillan, New York, New York, USA. 